\title{
Del texto al contra-texto
}

\section{From Text to Counter-Text}

\author{
Nicolás Garayalde \\ Universidad Nacional de Córdoba - Conicet \\ negarayalde@gmail.com
}

\begin{abstract}
What is a text? Can we know texts? Do texts exist? What are the limits of texts?

In the last twenty-five years, French literary studies seem to be undergoing a paradigmatic transformation that implies a reconceptualization of the notion of text (formerly thought of as an organic unit), whose outbreak occurred largely after the emergence of reception theories and deconstruction.

This new paradigm conceives text as a mobile object whose limits (external and internal) are difficult to specify. In this article, we will focus on the impact that certain psychoanalytic theories of reading have had on the way of thinking the concept of text, its space and its external limits, and the consequences this has had for literary criticism. For this, we will focus especially on the notion of counter-text.
\end{abstract}

\section{Key-words}

text, french literary criticism, psychoanalysis, reception theories, counter-text.

\section{Résumé}

Qu'est-ce qu'un texte? Comment peut-on les connaître? Existent-ils? Quelles sont leurs limites?

$\mathrm{Au}$ cours des vingt-cinq dernières années, les études littéraires françaises semblent avoir subi une transformation paradigmatique qui implique une reconceptualisation de la notion de texte (autrefois considéré comme une unité organique), dont l'éclosion s'est produite en grande partie après l'apparition des théories de la réception et de la déconstruction.

Nous croyons que ce nouveau paradigme considère le texte comme un objet mobile dont les limites, externes et internes, sont difficiles à définir. Dans cet article, nous nous centrerons sur l'impact de certaines théories psychanalytiques de la lecture, sur la façon de penser le texte, son espace et ses limites externes, ainsi que sur les conséquences qui en résultant pour la critique littéraire. Pour cela, nous allons nous intéresser plus particulièrement à la notion de contre-texte.

\section{Mots-clés}

texte, critique littéraire française, psychanalyse, théories de la réception, contre-texte. 
Anales de Filología Francesa, n. ${ }^{\circ}$ 28, 2020

Del texto al Contra-texto

\section{Introducción: de la obra al texto... y más allá}

En suma, lo que hemos descubierto es que no sabemos muy bien qué es verdaderamente un texto. No estamos ni siquiera seguros de que los textos existan. (F. Schuerewegen).

¿Qué es un texto? ¿Podemos conocer los textos literarios? ¿Tienen límites identificables? ¿Cómo es el espacio del texto? ¿Existen los textos?

En el campo de los estudios literarios, nada parece ir más contra el sentido común que el cuestionamiento de la existencia de los textos, cuya realidad nos parece tangible y evidente. Si los textos no existen, ¿qué es lo que hacemos cuando los leemos y cuál es la razón de ser de una disciplina que se dedica a su estudio? Es comprensible, por lo tanto, el estupor de aquel colega de Stanley Fish (1980), profesor de literatura inglesa, cuando una alumna se acerca para preguntarle si habrá textos en su curso, esto es, si en su clase se cree en algo llamado texto. Sin embargo, en las últimas décadas, algunos autores han comenzado a poner en cuestión la existencia de los textos y, con ello, el objeto de la teoría y la crítica literarias.

La historia de la teoría literaria podría parecer penosa para aquellos visitantes que posan la mirada sobre los devenires de su objeto. Porque desde este punto de vista, es la historia de una singular y esforzada lucha cuyos periplos parecen no haber encontrado nunca un feliz destino, si entendemos por ello la constitución de un objeto estable, homogéneo y no heteróclito, para usar un adjetivo que gustaba a Ferdinand de Saussure. Ciertamente, la perspectiva constituye el hecho, pero es tentador ver en la teoría literaria una serie de fracasos, en la medida en que su gesto fundacional fue la identificación de un objeto que le diera a la disciplina su autonomía y la separara de una vez por todas de una estética al servicio de la filosofía o de la historia. Tentadora es también la opción que sirve de un consuelo que puede adquirir, por momentos, dimensiones hiperbólicas: allí donde la constitución del objeto fracasa -según este consuelo- es donde la teoría literaria encuentra su mayor virtud, puesto que la incesante subversión del objeto responde a una evolución que no se deja inmovilizar por la fascinación de aquello que estudia -es decir, aquello que ha configurado como digno de su mirada ${ }^{1}$ - y de esta manera es capaz de tejer su propia defensa contra el sentido común y la creencia en un metalenguaje. Como sea, entre la literaturidad formalista y lo que se dio en llamar "el estallido del objeto" (Robin, 1989), lo que ocurre es la producción de un conocimiento preciso y valioso: la fulminante crítica a la concepción ontológica, metafísica y esencialista de la literatura.

Desde hace un tiempo, sostengo la hipótesis según la cual esta crítica ha sido posible por dos estocadas fulminantes que la teoría literaria ha dirigido a las pretensiones de una ciencia de la literatura: 1) los distintos modos de ser de la deconstrucción (término que em-

1 En efecto, la palabra teoría implica etimológicamente la acción de la mirada: del griego theória, "contemplación, especulación, la parte contemplativa de una ciencia o arte" (Monlau, 1856: 428). 
pleamos en un sentido amplio para referirnos a la lectura atenta que puso en evidencia, en los autores más diversos, la imposibilidad de la clausura del sentido y de la unidad del objeto); 2) las diversas variantes de las teorías de la recepción (que se desarrollan sobre todo a partir de la década de los 60, aunque sus articulaciones son de larga data). ${ }^{2}$ El entramado de estos dos gestos largamente presentes en el pensamiento sobre la literatura, pero cuya sistematicidad definió la constitución de la teoría literaria, ha conducido, me parece, al gran logro de la disciplina. Logro heroico, porque su precio es la constante desarticulación de los fundamentos que sostienen el edificio disciplinar y, con ello, uno de sus pilares fundamentales: el objeto.

En esto es paradigmático ese avatar del objeto que es el texto, imperante en los tiempos en que la disciplina se vio fascinada por el lenguaje estructuralista. Las peripecias del concepto de texto son a su vez una buena alegoría de las aventuras de la disciplina porque el mismo refinamiento metodológico que forjó su nacimiento terminó por dislocar su identidad.

Cuando la teoría literaria dejó a un lado las condiciones de producción (el autor, el contexto, la historia) como eje metodológico y se focalizó en el texto y su inmanencia, la pretensión -exacerbada en el New Criticism, cautelosa en el estructuralismo- de su unidad como entidad acabada prontamente encontró sus limitaciones, como efecto de un desbarajuste que Louis Hay expresó con claridad en un ensayo titulado "Le texte n'existe pas" (1985): "Lo que caracteriza al abordaje estructuralista es fundamentalmente un hiato entre una teoría nueva y un objeto viejo: el texto pensado como un producto acabado. De allí la necesidad de una segunda etapa teórica consagrada a la construcción de un nuevo objeto" (150). Esta etapa, que Louis Hay define como posestructuralista, no es sino el paso lógico de la misma aventura estructuralista. El nombre de Roland Barthes resume este pasaje, y su ensayo "De l'œuvre au texte", publicado en 1971, da cuenta precisamente de la emergencia de un objeto que nada tiene que ver con la vieja metáfora de la unidad orgánica. Se inicia aquí no sólo una nueva configuración del objeto sino también del quehacer crítico: "la lógica que regula el Texto no es comprehensiva (definir lo que la obra 'quiere decir') sino metonímica: el trabajo de las asociaciones, de las contingencias, de las relaciones, coincide con una liberación de la energía simbólica" (Barthes, 2002: 911).

Podría verse aquí el punto de inicio de aquella etapa a la que Hay refiere con posestructuralismo en lo tocante al objeto, y cuya consecuencia es tal grado de desustancialización del texto que su existencia y las posibilidades epistemológicas de su conocimiento caen bajo sospecha, gracias a una articulación entre la deconstrucción y las teorías de la recepción. Se trata de un cuestionamiento a aquello que Michel Charles (1995) llamó los dos prejuicios de la crítica frente al texto: el de su existencia; el de su unidad. En todo caso, Charles termina por asumir la posibilidad de una y otra cosa, aunque modifica el estatuto temporal, y por tanto ontológico: el texto existe como efecto de la lectura y no al revés; su unidad es efecto de la coherencia interpretativa, y no a la inversa. A los prejuicios, Charles contesta con dos

2 He procurado desarrollar esta hipótesis en distintos trabajos orientados a tratar problemas de la teoría literaria. Al respecto, $c f$. Garayalde (2018a, 2019). 
postulados: "la interacción texto-comentario" y "el texto como variación". Esto es, un texto existe a partir de su comentario y por ello mismo es efecto de una incesante variación. Se trata de una práctica coherente con el paradójico supuesto teórico del que se parte: si los textos no existen sino después de ser leídos, entonces sólo podemos relacionarnos con uno de sus posibles, es decir, con la singularidad que resulta de cada experiencia de lectura. La crítica literaria se aleja así de la hermenéutica y se acerca a la retórica que dominó la enseñanza de la literatura durante siglos: la de la lectura como pasaje a la escritura. En consecuencia, emerge una crítica que ha asumido diversos nombres (inventiva, intervencionista, postextual) y que define la escritura de un gran número de críticos franceses contemporáneos, muchos de ellos discípulos de Charles: Franc Schuerewegen, Marc Escola, Sophie Rabau, Pierre Bayard, por nombrar sólo algunos. El tiempo valorará la importancia teórica de estas nuevas expresiones críticas que han surgido en Francia a partir de la década de los 90. Pero para alguien como Escola puede "percibirse como un cambio de paradigma en el campo actual de los estudios literarios" (2011: 43).

¿En qué consiste este cambio de paradigma? Sin pretensiones de responder la pregunta en todas sus facetas, aventuremos una respuesta que este artículo se propondrá considerar: esta transformación paradigmática (que tomará la forma de "crítica intervencionista"3) se fundamenta en una reproblematización del concepto de lectura, a partir de la cual se fractura la existencia y la unidad del texto como objeto de conocimiento.

Podríamos considerar que se trata de un problema de límites, en la medida en que se diluyen las fronteras entre sujeto y objeto, lector y texto, lectura y escritura. Si el texto existe sólo como constructo interpretativo y no tiene una unidad previa sino que su identidad se define en cada acontecimiento de lectura y de modo diferencial: ¿cuáles son sus límites? Cuando leemos un texto, ¿qué leemos?, ¿dónde comienza y dónde termina nuestra lectura?; ¿es posible establecer los límites que señalen el comienzo y el final, el adentro y el afuera?; ¿cómo se aborda un texto?; ¿cuáles son los límites de su interpretación? En definitiva: ¿qué es un texto?

Jacques Derrida se ocupó seriamente de los límites del texto en "Living On: Border Lines", cuando se propuso abordar un poema de Shelley: "Si tenemos que abordar un texto, éste debe tener un borde" (1979: 83). Pero en cuanto se pretende encontrarlo, la experiencia demuestra que el texto se desborda por elementos que fisuran sus fronteras y que "nos obligan a extender el concepto acreditado, la noción dominante de un texto [...] que de ahora en

3 Crítica intervencionista es el nombre que algunos teóricos franceses comenzaron a emplear para referirse a los ensayos de Pierre Bayard. La primera aparición que hemos registrado data de 2004, cuando Marielle Macé la emplea para describir la operación crítica desarrollada por Bayard en la que se crean "variantes" de un texto literario. Desde entonces, varios autores (Samoyault, 2005; Escola, 2011) utilizan el término para dar cuenta del tipo de labor interpretativa de Bayard, quien termina por asumir la expresión cuando en abril del 2011 dicta en Grenoble un curso titulado "Introduction á la critique interventionniste". En todos estos casos, se la define como una crítica que cuestiona los límites que la separan de la literatura y que se propone escribir los textos posibles que existen virtualmente en una obra. 
adelante ya no será un corpus acabado de escritura, un contenido encerrado en un libro o sus márgenes, sino una red diferencial, un tejido de trazas que refieren sin cesar a algo distinto de sí mismo" (Derrida, 1979: 83-84). ¿Cuáles son los elementos que obstaculizan el establecimiento de un borde del texto, su estabilización, y lo configuran como un proceso de textualización incesante? ¿A qué se debe el desborde del texto que nos obliga a extender el concepto?

El presente trabajo se propone volver sobre el problema del texto (sus límites, su espacio) en los estudios literarios a la luz de la transformación paradigmática percibida por Escola. Para ello, partiremos de la siguiente hipótesis: la reproblematización del texto operada por algunos críticos franceses contemporáneos opone a la identidad y a la unidad del texto una doble fractura: psicoanalítica y retórico-deconstruccionista. La primera, refiere a la implicación del sujeto en la lectura, acusando la importancia de las teorías de la recepción desarrolladas desde la década de los 60 (lo que se vincula a lo que llamaremos "los límites externos del texto"); la segunda, alude a la naturaleza múltiple y diseminante del entramado textual, dando cuenta de la presencia de la deconstrucción en la retórica contemporánea (lo que se relaciona con lo que nombraremos "los límites internos del texto").

En este artículo nos dedicaremos al problema de los límites externos del texto, tratando los internos con ocasión de un trabajo futuro. Ambos tipos, a su vez, se corresponden con aspectos del texto que buscaremos conceptualizar: por un lado, llamaremos "hipertexto" a aquel aspecto que se refiere al desborde ocasionado por el carácter retórico y lingüístico del texto; por el otro, hablaremos de "contra-texto" para aludir a la implicación del sujeto de la lectura. A falta de un mejor término -y lamentando el uso de un neologismo tan extravagantellamaremos "hipercontratexto" al concepto que emerge en el entramado de la materialidad del texto y su recepción. Este concepto nos permitirá, esperamos, comprender mejor la topología del texto: esto es, su espacio, sus límites, sus continuidades, sus variaciones.

\section{Los límites externos: el marco de referencia}

Durante la segunda mitad del siglo XIX, en las épocas de Charles Augustin SainteBeuve, de Hippolyte Taine y de Gustave Lanson, el centro de la obra misma -su sentido, su valor- se encontraba fuera de ella: bastaba recurrir a las condiciones sociohistóricas, a la vida del autor, a su raza, a su género, a su psicología, para salvar los obstáculos que la distancia histórica suponía en el acceso a la obra ${ }^{4}$. Tiempo después, entrado ya el siglo XX, cuando las modas teóricas expulsaron de su campo de interés todo aquello que no perteneciera al texto, la contradicción no mermó y un elemento sustituyó a otro. La historia cedió el lugar a la literaturidad, la vida cedió el lugar a la estructura; pero todavía el centro estaba paradójicamente

4 Habría que ser justos, sin embargo, con G. Lanson, quien en su Histoire de la littérature française advierte que la originalidad de la obra literaria reside en el resto que queda tras haber aplicado "los métodos de determinación” (1966: vii). Lo que no significa que estos métodos no sean necesarios para acceder a la comprensión de las obras. 
afuera: en los formalistas, la literaturidad depende de su percepción ${ }^{5}$ y de las relación que la obra mantiene con otros sistemas"; en el estructuralismo, como bien lo advirtió Derrida, "el centro está en el centro de la totalidad y sin embargo, porque el centro no le pertenece, la totalidad tiene su centro en otro lado" (1971: 410).

En un caso como en otro, la astucia radicaba en una delimitación que parece arbitraria, fundamentada en todo caso en una necesidad de trazar un objeto estable y controlar la dispersión del sentido desde un punto que se defina como el centro de la estructura pero que a la vez no permanezca regido por las leyes de su juego: ¿dónde situamos el límite entre un adentro y un afuera de la obra? Por poner un ejemplo: ¿es el autor algo que está fuera de la obra? Como he tratado de demostrar en otro trabajo ${ }^{7}$, la resurrección del autor que tuvo lugar a partir de la década de los 90 significó, en muchos casos, su textualización, al punto en el cual su figura - por tomar un término de M. Couturier (1995)- corre la misma suerte interpretativa de la obra que se le adjudica. El autor es un elemento más del texto, sujeto a la elaboración del lector. Los ejemplos podrían continuar y toda exterioridad ser absorbida por el argumento interpretativo. Esta falta de exterioridad que estabilice el sentido y organice la estructura unitaria de la obra es parte responsable de ese pasaje -ubicado en el corazón del posestructuralismo- que va de la pregunta hermenéutica (¿qué significa este texto?) a la epistemológica (¿cómo conocemos el texto?).

Lo que está en juego aquí es la posibilidad de establecer un marco de referencia delimitado que regule la cartografía de la obra, aquello que Derrida, en La vérité en peinture de 1978, aborda a partir de la noción de parergon en I. Kant, es decir, el marco u ornamento de un cuadro, elemento marginal que rodea la obra propiamente dicha (ergon). Derrida interroga el lugar del parergon, el carácter accesorio que se le atribuye a la vez que advierte que el marco cuestiona la separación entre lo esencial y lo marginal: "No sé qué es esa cosa, ni esencial ni accesoria, no propia ni impropia, que Kant llama parergon, por ejemplo el marco. ¿Dónde tiene lugar? ¿Tiene lugar? ¿Dónde comienza? ¿Dónde termina? ¿Cuál es su límite interno y externo?" (Derrida, 2010: 73). La dificultad proviene del dinamismo de la obra, experimentada en su movimiento y recreación, de modo tal que su cartografía no presenta siempre los mismos límites.

Tiempo atrás, en un artículo de 1936, Jan Mukarovsky también había evocado este dinamismo en la obra literaria al descartar, como Derrida, una concepción ligada a la noción de ergon: "La variabilidad pertenece a la esencia misma del valor estético, el cual no es un estado, ergon, sino un proceso, energeia" (2011: 75). La variabilidad del valor toca la de la obra, que, artística en una época, puede dejar de serlo en otra. Este fenómeno encuentra su

5 "El carácter estético de un objeto -nos dice Viktor Shklovski en su célebre artículo "El arte como artificio"-, el derecho de vincularlo a la poesía, es el resultado de nuestra manera de percibir" (2008: 79).

6 Nos referimos aquí a los planteos de I. Tinianov (2008) en su concepción del hecho literario como determinado por la relaciones entre elementos del propio sistema (función sínoma) y con otros sistemas (función autónoma).

7 Cf. Garayalde (2018b). 
explicación en una necesaria distinción que Mukarovsky establece entre el artefacto material (fijo, estable) y el objeto estético, "que representa el correlato de aquel en la conciencia del receptor", de tal modo que "es variable, pues está determinado no sólo por la configuración y las propiedades del artefacto material sino también por la correspondiente etapa evolutiva de la estructura artística inmaterial” (2011: 104). ¡Cuán necesaria resulta esta distinción al considerar la cartografía del texto y separar la confusión que el libro produce como ilusión material! No en vano Hillis Miller llamó al libro como objeto físico un "poderoso soporte del logocentrismo" (2005: 237) ${ }^{8}$. Cuando nos preguntamos por los límites externos del texto, entonces, no nos preguntamos por aquellos que pueden establecerse a partir del artefacto material, sino los del objeto estético, es decir, como diría Mukarovsky, de su correlato en la conciencia del receptor.

No es casual, por ello, que en "Extension et incertitude de la notion de littérature", Régine Robin haya incluido, entre los motivos que explican el estallido del objeto en los estudios literarios, la intervención de las teorías de la recepción, en la segunda mitad del siglo XX: "se constituyó un nuevo dominio que ya no mira la literatura desde el ángulo de la creación o del biografismo, o del texto por el texto [...], sino que la considera a partir del plano sociológico de los lectores reales, de los actos de lectura reales, que llegan incluso hasta modificar el estatuto del texto” (1989: 48). ¿Cuál es esta modificación que la perspectiva de la recepción produce sobre el estatuto del texto?

En primer lugar, sería necesario decir que lo que Robin llama "intervención de la recepción" en los estudios literarios es un fenómeno complejo y heterogéneo, atravesado por paradigmas teóricos no sólo diferentes sino a menudo contradictorios: "los teóricos orientados al lector -decía con razón P. Rabinowitz- sorprenden más por sus desacuerdos que por sus puntos de coincidencia" (2010: 413). De esta manera, partiendo de la importancia que cabe al lector, los distintos teóricos modificarán de diferentes modos el estatuto del texto.

En segundo lugar, debemos señalar que el reconocimiento de la implicación del lector en la constitución del texto no es algo novedoso en la teoría literaria, y se encuentra en sus orígenes, cuando los propios formalistas, exhibiendo la influencia de Edmund Husserl, acuñaban la noción de "extrañamiento" como clave de delineamiento del hecho literario. No es casual que esta misma influencia haya estado en los fundamentos de lo que décadas después se llamaría la Rezeptionsästhetik, donde aparece con vehemencia la necesidad de considerar el polo de la lectura para el estudio de las obras literarias. Sin embargo, el rechazo de Husserl al psicologismo empírico, rechazo que tan bien se había adaptado al de los formalistas, sigue vigente aquí de tal manera que la estética de la recepción se cuida muy bien de no quedar atrapada en la psiquis del receptor. Como consecuencia, los dos portavoces más importantes del movimiento producen o bien una "teoría del efecto", que busca en el texto las condiciones de

8 "Las páginas están en orden -afirma Miller-, con un margen que enmarca las línea con un borde blanco, justificado, como se dice, sugiriendo algún tipo de responsabilidad ética o judicial que mantenga de manera clara y firme las fronteras entre el signo pleno de sentido y el blanco insignificante" (2005: 238). 
la actualización lectora (W. Iser), o bien una "teoría de la recepción", preocupada en pensar la historia de la literatura como una serie de respuestas colectivas (H. R. Jauss). Cuando Mukarovsky habla del texto como un "correlato de conciencia en el receptor" y cuando, más tarde, Iser expresa que la comunicación literaria "se realiza en la medida en que el texto aparece en el lector como correlato de la conciencia" (1987: 175), lo que se encuentra detrás es una fenomenología que no debe confundirse ni con empirismo ni con psicología: la consciencia no es algo que está "adentro", sino que, en tanto consciencia intencional, "consciencia de algo", es un punto de unión entre el adentro y el afuera cuya ligazón es la percepción ${ }^{9}$. Por ello, el objeto de la teoría del efecto de Iser se interesa no por la manera en que el texto es elaborado por los procesos psíquicos del lector, sino por la arquitectura textual que guía la actividad de concreción que el lector lleva a cabo, a fin de conjurar todo subjetivismo que entienda la obra en términos de percepción particular: "Si se determina el proceso de lectura como la actualización del texto, entonces podemos preguntarnos si tal actualización es describible de algún modo sin caer al mismo tiempo en una psicología de la lectura" (Iser, 1989: 133).

Esta posición fue largamente cuestionada por el teórico norteamericano Norman Holland, quien veía allí un retorno al lector ${ }^{10}$ que, sin embargo, sólo hablaba del texto. En una conversación publicada en 1980 en la revista Diacritics, Holland reclamaba a Iser que, diciendo interesarse en la respuesta lectora, se basaba en evidencias filosóficas fenomenológicas sin prestar nunca atención a lo que los lectores empíricos hacen. Admitiendo la acusación, la respuesta del profesor de Constanza señaló, sin embargo, la necesidad de construir primero un modelo heurístico de las actividades básicas para el procesamiento de textos. Porque estas asunciones heurísticas son necesarias para saber cualquier cosa de la respuesta de un lector empírico: "por lo tanto, nuestro primer requisito es un marco de referencia con el cual podamos relacionar nuestros descubrimientos" (Iser, 1980: 62). A la herencia fenomenológica deberíamos agregar, para explicar este anti-psicologismo, el temor a caer en una concepción relativista del texto. La estrategia de Iser radica, por ello, en el establecimiento de un marco de referencia basado en la estructura apelativa de los textos: sus estrategias, repertorios y lugares de indeterminación que guían el proceso de concreción de la lectura. ${ }^{11}$

A esta concepción Holland opone un modelo transaccional que considera la lectura

9 Este antipsicologismo es explícito en Mukarovsky, quien afirma el célebre ensayo "El arte como hecho sígnico": "La obra de arte no puede ser identificada, como lo pretendía la estética psicológica, con el estado psíquico de su autor, ni con los diversos estados psíquicos suscitados por ella en los sujetos receptores. (...) Todo estado de conciencia subjetivo posee algo de individual y momentáneo que lo hace inasible e incomunicable en su conjunto, mientras que la obra de arte está destinada a mediar entre su autor y la colectividad" (2000: 88).

10 Hablamos de "retorno al lector" porque, en efecto, el lector había sido ya objeto de interés durante el siglo XIX aunque desde una perspectiva completamente diferente, ligada más al afecto que al procesamiento intelectual. Al respecto, cf. los libros The Return of The Reader (1987) de E. Freund y Theories of Reading (2006) de K. Littau.

11 La crítica de Holland es también deslizada por Antoine Compagnon, al denunciar cierta hipocresía en el interés que la teoría del efecto de Iser tendría sobre el rol activo del lector: "Bajo la apariencia del liberalismo más tolerante, el lector implícito no tiene en verdad otra opción que la de obedecer las instrucciones del autor implícito, porque no es más que su alter ego o su avatar" (Compagnon, 1998: 180). 
como una experiencia de recreación de la identidad del lector, que es entendida como un tema y sus variaciones. Sujeto y objeto se enlazan en la medida en que no es posible conocer un texto sin alterar su percepción objetiva mediante un complejo entramado de fantasías y mecanismos defensivos propio de cada lector y que definen su mito o modo de ser. Señalando también una influencia fenomenológica, pero ambicionando evitar una metafísica de la percepción trascendental, Holland se precipita hacia lo empírico, para trabajar con la respuesta que un conjunto de lectores ofrece frente a un mismo "texto": 5 Readers Reading, libro de 1975, es así una detallada descripción de cómo cinco estudiantes leen a partir de sus identidades el cuento "A Rose for Emily" de W Faulkner. Según Holland, el resultado de este experimento es concluyente: cada lector utiliza el relato de Faulkner para crear a partir de allí un texto como réplica de su propia identidad, en la medida en que esto supone una ganancia de placer como modo de cumplimiento de las fantasías allí implicadas bajo la protección defensiva que ofrece el material literario. Esta tesis explicaría no sólo qué hacemos cuando leemos sino también por qué leemos. Esta posición, sin embargo, no carece de dificultades.

En primer lugar, surge una dificultad de orden epistemológica y metodológica: ¿con qué criterio se comparan las respuestas si la interpretación que Holland hace tanto del cuento de Faulkner como de las lecturas de los estudiantes está ya mediada por su propia identidad? Se podrá creer que llevo demasiado lejos su argumento; a mi favor, basta citar al propio autor: "Después de todo, un texto literario, en un sentido objetivo, consiste sólo en cierta configuración de manchas de carbón negro en pulpa de madera seca" (1975: 12). Pareciera que esta posición se ve amenazada por una contradicción: por un lado, corre el riesgo de precipitarse hacia un solipsismo monológico que no sólo impide todo acceso a un texto literario sino también a toda respuesta lectora; por otro lado, y por este motivo, toda su investigación cae bajo sospecha en la medida en que asume la posibilidad de interpretar las identidades (que no son más que otros textos) de sus estudiantes y sus respuestas. Holland parece pretender estar exento de las leyes que su propia teoría impone a la experiencia de lectura.

En segundo lugar, se da una dificultad de orden pragmático: si cada lector recrea su identidad en cada experiencia de lectura, proyectando masivamente sus fantasías y mecanismos defensivos como si el texto fuera -según advierte Iser (1980)- un test de Rorscharch, ¿cómo se evitaría caer en un solipsismo relativista? La identidad bien puede explicar las diferencias entre lectores, pero ¿cómo explica las semejanzas?

Frente a la primera dificultad, podemos conceder que la frase que define el texto como manchas de carbón en pulpa de madera seca exige una lectura retórica: se trata de una hipérbole que reduce el texto a su materialidad como estrategia argumentativa con el fin de señalar la importancia del sujeto en la experiencia literaria y la imposibilidad de evitar la deformación que su lectura ejerce. Después de todo, ¿es muy lejana la caracterización que un agudo lector come Terry Eagleton hace del concepto de texto en la estética de la recepción?: 
"En la teoría de la recepción, el lector concretiza la obra literaria que en sí misma no pasa de ser una cadena organizada de signos negros estampados en una página" (2002: 98).

Aun así, el problema metodológico de la comparación de lecturas permanece, y parece el precio que paga Holland para sostener una radical configuración epistemológica de la existencia del texto: el texto literario es objetivamente imposible de conocer y toda conceptualización que se pretenda exhaustiva no puede excluir la parte que toca a la psicología de la recepción, sencillamente porque el texto es un efecto de lectura y no su causa. En todo caso, y a pesar de esta contradicción que amenaza derrumbar la arquitectura empírica y argumentativa de su trabajo, el mérito de Holland radica en la demostración de la naturaleza subjetiva del texto y en el intento de elaborar desde el psicoanálisis una teoría explicativa del modo en que la injerencia psicológica del lector se produce. Es algo que, después de todo, termina por suceder a un colega de Iser como H. R. Jauss, quien reconoce que su primer proyecto de la estética de la recepción no lograba explicar "por qué en una determinada época [un texto] fue entendido de una manera, y después de otra, [lo que] exige algo más que la reconstrucción del horizonte de expectativas intraliterario implicado por la obra"; para luego agregar: "a mi proyecto le faltaba todavía la explicación psicológica” (1987: 62-63).

Como es posible observar, toda la distancia entre la perspectiva de Iser y la de Holland parece radicar en el lugar en el que se sitúa el marco de referencia: si para el primero el marco de referencia que regula el texto como correlato en la consciencia del lector $-y$ por lo tanto sus límites-radica en las estrategias y repertorios textuales que determinan -aún en su indeterminación- la creación del objeto estético; para el segundo ocurre exactamente lo contrario, en cuanto es la identidad del lector empírico lo que constituye el marco de referencia que determina la ideación en su consciencia -inconsciente involucrado- del objeto estético ${ }^{12}$.

Asumamos entonces, si pretendemos que el entramado argumentativo de Holland no sucumba ante la contradicción, que las manchas sobre pulpa de madera seca funcionan en cada artefacto textual como un estímulo condicionante que será singularmente apropiado y elaborado por la identidad del lector. Aun así, ¿cómo no caer, luego, en un solipsismo relati-

12 Afirmación que, de nuevo, habría que matizar, lo que revela la complejidad que el problema tiene tanto para Iser como para Holland: ambos parecen mostrar a lo largo de sus obras una vacilación constante en el peso que le otorgan a los elementos que determinan y delimitan el objeto estético. Así, ante las objeciones de Holland, Iser dirá, curiosamente, que "cada lector traduce la experiencia inducida por el texto en su propio marco de referencia, al que el profesor Holland llama su identidad" (1980: 63). De modo que parece asumirse aquí que la identidad supone un marco de referencia para el texto. Sin embargo, pronto se revela que no se trata de la identidad tal como la entiende Holland: "El "determinismo" implicaría por lo tanto no que el lector meramente proyecta su propia identidad en el texto, sino que esa identidad - que asume su forma a través de las actividades ideacionales guiadas por el texto- es un medio de hacerse cargo en su propio acervo de experiencias de algo que hasta entonces era extraño para él. Por supuesto, la identidad tendría allí entonces una función completamente diferente de la que le atribuye el profesor Holland" (1980: 63). Del otro lado, la vacilación también se percibe: en efecto, Holland a veces atribuye al lector la total elaboración del texto a partir de manchas de carbón en pulpa de madera seca; otras veces asume una concepción retroalimentativa no lejana a la afirmación de Iser. Así, Holland entiende, también, que la literatura modifica el acervo de experiencias del lector, actuando sobre las variaciones de su tema identitario. 
vista? Nos enfrentamos aquí a la segunda dificultad que señalamos más arriba. La respuesta de Holland llega en 1992 en The Critical I, donde acopla su perspectiva psicoanalítica al pragmatismo de Stanley Fish. Aparece entonces un concepto más ampliado de marco de referencia que asume a veces el nombre de contexto y otras el de "comunidades interpretativas": es decir, un grupo social que comparte un conjunto de supuestos y estrategias interpretativas que existen antes del acto de lectura y "determinan la forma de lo que es leído antes que, como en general se asume, al revés” (Fish, 1980: 171). Pero las comunidades interpretativas no tienen más estabilidad que el texto que producen: son convencionales, son constructos sociales y están, por lo tanto, sujetas a una transformación permanente.

Que el contexto suponga también una interpretación afecta su estatuto epistemológico, y allí radica uno de los distanciamientos de Fish respecto a las posiciones esencialistas y fundacionalistas. Por un lado, se niega un sentido transcontextual del texto, es decir, un sentido independiente de su inscripción contextual. Pero, por otro, se niega también un contexto fijo y estable a partir del cual establecer un contraste: "todos los textos son igual y radicalmente huérfanos en el sentido en que ninguno de ellos está atado con seguridad a un estado de cosas independientemente especificable" (1982: 700). Fish está asumiendo, de esta manera, la posición que Derrida sostiene en "Living On", cuando afirma: "ningún contexto es saturable. Ninguna inflexión goza de un privilegio absoluto, ningún significado puede ser fijado o determinado. Ningún borde está garantizado, dentro o fuera" (1979: 78).

De acuerdo a este razonamiento, no existe un contexto de permanencia, un marco de referencia exhaustivamente determinable que desde un afuera detenga la movilidad del texto; un contexto cuyas claves interpretativas sean legibles para cualquiera independientemente de su posición. El contexto no es algo que está en el mundo, sino una construcción que emerge de condiciones que están a su vez contextualizadas. Por ello, los contextos no pueden regular y fijar un sentido del texto demarcando sus límites: porque son productivos para la interpretación pero también son el producto de ella. Así, el estatuto y los límites de un texto se definen en cada lectura y el contexto no está más afuera del texto que su autor, la identidad del lector o las estrategias y repertorios textuales.

La propuesta de Fish, entonces, permite a Holland sostener su concepto de identidad (como modo de responder las diferencias entre los textos producidos por cada lector) sin caer en un solipsismo relativista mediante la incorporación, en su modelo transaccional, de las nociones de códigos y cánones:

Algunos de los esquemas que aplicamos al mundo son flexibles, mientras que otros son
muy estrictos, tan estrictos como para constituir una norma. [...] Si pensamos en el
simple acto de leer una carta, nos damos cuenta de que no la podemos leer de otro modo
que aquél que el código prescribe. No puedo leer una $g$ como algo diferente a una $g$. El
proceso es: veo (por medio de una retroalimentación fisiológica) manchas de tinta en
una página. Pruebo en la sensación parcialmente procesada la hipótesis que aprendí de
niño en esta cultura para la lectura de caras. De la hipótesis para $g$, obtengo una retroa- 
limentación positiva, y el bucle se cierra ajustadamente, no admitiendo la posibilidad de $f$ o $z$. [...] Sugiero los términos códigos y cánones para dividir las reglas de acuerdo a su "poder ser de otra manera". Mediante esta definición, los códigos no pueden, si estás funcionando como un miembro normal de la cultura, ser de otra manera. Todos usamos códigos para saber que una $g$ es una g. Los cánones pueden ser de otro modo, dependiendo de a qué comunidad interpretativa pertenezcas dada una cultura determinada (1992: 33-37).

A partir de la identidad se usan códigos y cánones para servir a los deseos conscientes e inconscientes de cada sujeto: "Incluso los códigos culturales más rígidos -dice Hollandsirven a las necesidades personales" (1992: 38). En otras palabras: incluso los códigos más estrictos se adaptan a las fantasías y mecanismos defensivos del individuo. La relación entre identidad, códigos y cánones establece así un sistema retroalimentativo como marco de referencia a partir del cual se elabora el texto. Pero en la medida en que la lectura es un proceso de replicación de la identidad (y de los códigos y cánones que porta), no podemos decir que es algo que está fuera del texto; más bien, se encuentra en su mismo entramado. Acompañada de la perspectiva fisheana, la noción de identidad da lugar a la imposibilidad del determinismo del sentido. No sucede sólo porque siempre es posible imaginar una identidad diferente que interaccione con el texto y dé lugar a la emergencia del sentido como acontecimiento, sino también porque la identidad está sometida a las leyes de la interpretación. Ello lleva a Holland a remarcar la dificultad de precisar cuál es el espacio en el que se encuentra un texto: "En realidad sólo podemos conocer un texto literario a través del acto de percepción de algún lector que a ciencia cierta no nos dice nada -ini una palabra!- sobre la existencia o ubicación del texto" (2008: 150).

No lejos de este relativismo se encuentra Fish, quien al anteponer la interpretación a los textos nos sitúa ante la paradójica situación en la cual los textos son posteriores a la lectura. No es extraño, por lo tanto, que un Eagleton sorprendido pregunte: "¿qué es lo que Fish cree estar interpretando cuando lee?" (2002: 108). Esta pregunta, con lo demoledora que podría resultar, quizás sólo produzca su efecto en la medida en que la lectura sea pensada como una operación de decodificación frente a una escritura. Pero para Fish -como, de hecho, para Iser- la lectura es un proceso y el significado, un evento; la lectura es un acto de escritura que ocurre en la consciencia del lector: "considerar los enunciados de un texto como algo separado de la conciencia del receptor supone correr el riesgo de perderse lo que está sucediendo" (1980: 36).

Más allá de las diferencias entre Iser, Holland y Fish, más allá, incluso, de las contradicciones y problemas que hemos podido señalar, es notable cómo estas teorías de la recepción modifican sustancialmente la concepción del texto como algo que se encuentra fuera de la conciencia -sea el modo en que estos autores entienden esta noción, ora desde un punto de vista fenomenológico, ora psicoanalítico, ora pragmático-. A partir de las teorías orientadas a la lectura, surge la convicción no sólo de que el texto es inaccesible como una 
entidad objetiva sino que además no existe fuera de la creación interpretativa, lo que supone notables consecuencias para la crítica literaria. En esta tradición se ubica el concepto de texto que podemos encontrar en la transformación paradigmática que, según Escola, se ha producido en los estudios literarios franceses contemporáneos. Sólo que aquí podemos señalar, como hipótesis, un paso más: si las teorías de la recepción supusieron frente al concepto de texto un paso de la ontología a la epistemología ${ }^{13}$, la crítica francesa contemporánea parece demandar ahora un pasaje de la epistemología a la poética: el lector deviene escritor; el texto, construcción poética de lectura. En este punto, el psicoanálisis tuvo mucho que aportar.

\section{EI texto como objeto transicional}

Resulta lógico que desde el momento en que la teoría literaria asumió la implicación del lector en la elaboración del texto, el psicoanálisis se haya mostrado particularmente interesado en ofrecer conceptos que diluciden el asunto.

Si Holland había avanzado ya en este sentido, la teoría literaria francesa contemporánea parece mantener, sin embargo, una concepción crítica que se distancia del psicoanálisis del yo. Situado en la noción de identidad de Heinz Lichtenstein (y en la tradición norteamericana que, a partir de Alfred Adler, asentaría en la segunda tópica freudiana el fundamento de sus elaboraciones teóricas), Holland concibe la posibilidad de un conocimiento cabal del sujeto. Esto es, en él todo es simbolizable y, en la medida en que la identidad puede ser escrita, la unidad orgánica perdida en el texto se recupera en la lectura. Sin embargo, este modelo orgánico encontró objeciones en otros autores que, alineados en una tradición permeada por el pensamiento lacaniano, permanecieron atentos al resto simbólicamente inasimilable que habita al sujeto; posición que se traduce en una concepción del texto como reacción desviada y fallida de lo que leemos, involucrando no sólo la respuesta simbólica sino también la afectiva.

En este sentido resultan muy importantes dos autores cuyas teorías sobre la lectura son determinantes en el pensamiento de la crítica y teoría francesa contemporánea, y a partir de los cuales podemos trabajar la manera como el lector reconfigura los límites del texto: $\mathrm{M}$. Picard y P. Bayard.

En ambos la lectura aparece, al igual que en Holland, como una experiencia ligada a la repetición y a lo fantasmático; pero a diferencia del crítico norteamericano, esta experiencia es siempre fallida, y el lector no sólo no tiene acceso al texto como artefacto que se presenta ante sus ojos sino que tampoco al texto de su propia identidad ${ }^{14}$. ¿Qué lee, entonces, el lector?

13 En este sentido, el epistemólogo constructivista J. Bruner decía: "La novedad intelectual de cualquier generación no es que existe la realidad y el significado, sino que es extraordinariamente difícil determinar cómo se logran. La ontología, quisiera decir, se cuida sola. Es la epistemología la que necesita ser cultivada" (2012: 156).

14 Esta crítica destinada a Holland es válida también para Iser, en la medida en que la noción de "fusión de horizonte" -proveniente de la fenomenología de Hans-Georg Gadamer- remite a una relación entre el lector y el texto basada en una dialéctica en la que sujeto y objeto convergen en una fusión experiencial. 
Picard responde de una manera que puede resultarnos paradójica, pero que se sitúa precisamente en el intento de dar cuenta de esta imposibilidad ligada a la lectura: "el lector lee otra cosa de lo que cree estar leyendo -lee aquello que no está (para nada) escrito, y no puede estarlo" (1989: 107). ¿Qué es aquello que no está escrito ni puede estarlo?

Por un lado, está aquello que Picard -siguiendo una propuesta desarrollada una década antes por Jean Bellemin-Noël (1977)- llama "el inconsciente del texto", esto es, una red de significaciones inconscientes que atraviesan el tejido textual y cuya fuerza oblicua fomenta la escritura y la fermenta. Desligado de una subjetividad autoral, el inconsciente del texto funciona como una necesidad lógica de la alteridad que interpela y es interpelada por el inconsciente del lector, funcionando como una suerte de caja de resonancia que hace de la sesión de lectura una experiencia cercana a la sesión analítica. Picard se distancia así de lo que considera la posición "cuasi solipsista" de Holland: "La relativización excesiva de la recepción artística conlleva el riesgo de perder de vista lo que es quizás esencial en la lectura; a saber, la relación entre un sujeto y un texto. (...) Ningún juego nace de la nada" (1986: 142). Al ser pensada como un juego, la lectura se ubica topológicamente en el espacio potencial planteado por Daniel Winnicott, donde la estructura apelativa del texto supone el encuentro de inconscientes, bajo una lógica enmarcada ya no en el psicoanálisis del yo (como Holland) sino en el psicoanálisis de objeto ${ }^{15}$.

Por otro lado, lo que no está escrito ni puede estarlo es aquello que toca al inconsciente del lector y demanda una psicología a la que la estética de la recepción, como hemos ya señalado, parece no querer dar lugar: "sabemos a qué dificultades teóricas irremontables se enfrentaron el formalismo y la teoría de la recepción por carecer de una teoría coherente y una consideración del sujeto psicológico" (Picard, 1986: 146). Así, Picard entiende la lectura como un encuentro con la alteridad en la que se implica a la vez, sin embargo, la repetición de lo mismo, el retorno del fantasma como articulación simbólica de lo que en el sujeto falta y cuya imposibilidad de simbolización remite a lo que no está escrito ni puede estarlo. La paradoja de la lectura radica, psicoanalíticamente, en la experiencia de lo ya-leído, la repetición de lo mismo - es decir, de la experiencia pretérita, la recuperación del objeto perdido- a la vez que la imposibilidad de su recreación, la incesante e inacabable tarea del duelo de la pérdida, la lectura imposible de lo que en el sujeto escapa a la simbolización. En este esquema lo que lee el sujeto se encuentra afuera y adentro, entrelazamiento entre una alteridad y un fantasma personal en el que cada significante dice una cosa y otra a la vez, encontrando y elaborando simultáneamente el objeto.

Entre la alteridad y la imposibilidad de esa lectura de uno mismo, Picard concibe el texto como un objeto transicional, según una bella definición: "la ambigüedad profun$\mathrm{da}$, esencial, de ese objeto, bloque calmo caído de un desastre oscuro, a la vez inventado y encontrado, venido de otro lado; el texto, juguete complejo, es lo que hace surgir la alte-

$15 C f$. la clasificación de las escuelas psicoanalíticas pos-freudianas desarrollada por Tortosa y Civera (2006), 
ridad" (1986: 153). Objeto inventado y encontrado, interior y exterior a la vez, situado en el entrelazamiento de lo que resulta irreductible a lo simbólico tanto en el Otro como en lo propio, proveniente de lo más íntimo y, a la vez, de otro lado, el texto parece configurarse topológicamente en la paradoja de aquello que J. Lacan llamó lo "éxtimo". Este concepto, que parece adaptarse mejor que el de espacio transicional a la complejidad topológica del texto, delinea precisamente la diferencia con una perspectiva hollandiana. Al decir de J.-A. Miller -quien dedicó un seminario a este asunto- lo éxtimo expresa "el drama del sujeto tal como lo muestra la experiencia analítica, que es no lograr estar plenamente en casa" (2010: 25). De este modo, podemos encontrar aquí una conceptualización precisa en cuanto a la espacialidad del texto y sus fronteras: elaboración de lectura que surge en el cruce de resonancias inconscientes, entre la alteridad textual y el fantasma del lector como manifestación provisoria y repetitiva de lo que no puede estar escrito, esto es, de lo que en el sujeto falta. El texto se constituye así a partir de un lector pensado en su aspecto afectivo y pulsional (lo que Picard llama leído) y en su aspecto simbolizante (lo que llama lectante), aun allí donde esta simbolización encuentra un punto de detención, un límite.

Es notable que durante el tiempo en que Picard formula estas conceptualizaciones de la lectura, otros autores están proponiendo en Francia una manera de pensar el texto que resulta en muchos aspectos compatible y que expresa la emergencia -y la necesidad- de un nuevo objeto para los estudios literarios: el contra-texto.

\section{El contra-texto}

En 1977, Anne Clancier propuso un concepto que tendría un largo derrotero en las teorías literarias psicoanalíticas -y también en las no estrictamente psicoanalíticas- y que se encuentra implicado en la modificación del estatuto de texto en los estudios franceses contemporáneos: "llamo, quizás provisoriamente, mis reacciones de lectora y de analista del texto un contra-texto. Incluiré en esta categoría todas las reacciones, cualesquiera sean, que se pueden tener frente a la obra de un autor: atracción, interés, aburrimiento, irritación, desagrado, angustia, etc." (Clancier, 1977: 80-81). La particularidad de esta definición, si la comparamos con el modelo de lectura de Holland, es la focalización sobre la posición analítica en la que se sitúa la lectura: si en el teórico norteamericano la lectura se asimila a la posición del sujeto que va a análisis, quien reconstruye, mediante el pasaje por un otro que le presta su palabra, la propia identidad, en Clancier la lectura implica la posición del analista, cuya tarea no radica en la indagación y elaboración de su propio deseo, sino en la emoción disparada por el texto más allá del trabajo interpretativo. Esa es la razón por la cual, como insistirá tiempo después, el contra-texto se liga a la noción psicoanalítica de contratransferencia: "Por contra-transferencia podemos entender aquello que el analista siente al escuchar a su paciente. Análogamente, llamé contra-texto a aquello que diferentes autores 
me hacen sentir" (2014: 12). Curiosamente, Clancier prefiere ubicar al lector del lado del analista, pero simultáneamente construye la noción de contra-texto como reacción afectiva al texto, y no interpretativa.

Sobre este punto, años después, el concepto variaría al ser retomado por Pierre Glaudes (1990, 1993), para quien la definición de Clancier es incompleta en tanto que se restringe sólo a los afectos. En consecuencia, Glaudes la redefine y agrega las representaciones inconscientes, situando el contra-texto en la relación de partenaire que el lector mantiene con la obra que lee, es decir, con el trabajo inconsciente del texto. Por ello, el texto es entendido como el lugar de encuentro entre dos inconscientes: por un lado, el del texto (habitado por el inconsciente del enunciador); por el otro, el del lector. La fuerza enunciativa del texto está en suspenso hasta que no intervenga el inconsciente del lector. Como consecuencia, el texto se vuelve un lugar donde se anuda la contratransferencia del lector, es decir, "deviene el punto de encuentro de dos fuerzas inconscientes, a partir del cual el contra-texto podrá constituirse" (1993: 94).

Si el contra-texto se produce en esta interacción, el análisis del texto conduce, admite Glaudes, al análisis de uno. La interacción entre los inconscientes que sucede durante la lectura produce como consecuencia una experiencia de escritura: "el lector da forma al material que ha recogido, le confiere una estructura lógica y lo unifica alrededor de un manojo de significaciones que desembocarán en la formalización contra-textual” (1993: 99). El contratexto implica así una elaboración mediante un trabajo de sublimación. En otras palabras: una formación de compromiso. A diferencia de Clancier, Glaudes parece interesarse por lo tanto en el carácter representacional del contra-texto (lo que Picard llamaba la operación del lectante) y no sólo en su componente afectivo (lo que Picard llamaba la actividad del leído). La experiencia de lectura, así, se articula, se emplaza, a la de escritura.

El recorrido por la noción de contra-texto propuesta por Clancier y reelaborada por Glaudes nos permite observar algunos aspectos sobre el modo de entender el texto en el marco de la transformación paradigmática aludida por Escola y que se vinculan a la influencia del psicoanálisis en la teoría literaria.

En primer lugar, está la implicación del afecto, elemento ausente en las teorías de la recepción que, en su retorno al lector, privilegiaron la operación mental en desmedro de una crítica afectiva presente en las teorías del arte y la literatura hasta, al menos, la percepción desinteresada de $\mathrm{Kant}^{16}$. Por ello, la noción de contra-texto viene a subrayar el aspecto afec-

16 En este sentido, Karin Littau afirma: "Mientras que en la tradición retórica de la crítica el afecto y los efectos iban de la mano porque ambos términos deban cuenta de la capacidad de la literatura para mover y conmover al lector, a partir del siglo XVIII se fue produciendo una escisión entre lo que afecta y lo que tiene efectos" (2008: 144). Expulsado de la teoría literaria desde sus momentos fundacionales, herido de muerte por "The Affective Falacy" (Wimsatt y Beardsley, 1949, no sorprende por lo tanto que el afecto haya estado ausente en el retorno al lector de la década de los 60 y que un emblemático autor como Iser desarrolle, en contraposición, una teoría del efecto. $\mathrm{Y}$ en aquellos casos en los que el afecto ingresó en las consideraciones de la experiencia estética, como en Jauss y Holland, aparece supeditado a la construcción del sentido en términos hermenéuticos: "Pese a todo lo que se dice sobre los sentimientos subjetivos que experimentan los lectores -afirma Littau-, Holland 
tivo de la lectura no necesariamente ligado a la representación. Esto es particularmente cierto en la manera en que Clancier lo entiende, quien en una entrevista publicada en 2014 aceptará la posibilidad -señalada por Glaudes- de considerar el significado en el contra-texto, pero manteniendo una primacía del afecto: "En mi espíritu, el contra-texto está del lado de los afectos suscitados por el texto, su elaboración intelectual lo excede. (...) Entre emoción e interpretación, las fronteras no son herméticas. Pero la emoción prevalece en el uso que hago del contra-texto" (Clancier, 2014: 13).

En segundo lugar, la elección de situar el contra-texto del lado de la contratransferencia (es decir, del lado del analista) nos indica sin embargo, y quizás paradójicamente, la necesaria implicación analítica entramada a lo afectivo en el contra-texto, tanto más aún a partir de la reelaboración de Glaudes. ¿Por qué si no hablar en términos de contratransferencia y no simplemente, como sería adecuado a un teoría de la lectura psicoanalítica al estilo de Holland, de transferencia? La razón podría encontrarse no sólo en la indirecta manera de indicar la presencia del acto interpretativo -después de todo, la noción de analizante, propuesta por Lacan, supone una posición activa de quien va a análisis, de manera tal que la elaboración del sentido es un trabajo en conjunto-, sino sobre todo en la puesta en consideración de una ética de la escucha. Frente al lector de Holland-siempre a punto de constituirse en una identidad autosuficiente, retroalimentada por su propia lógica de la repetición orgánica-, el contra-texto subraya el encuentro con el otro, una ética de la escucha del texto, a la vez que el hiato en la unidad del yo.

Ciertamente, el concepto de contra-texto permite estas elucubraciones y es así como su derrotero conceptual lo abrió a una pluralidad por momentos paradójica. Basta ver, en este sentido, el diverso dossier sobre contra-texto que publicó el número 12 de la revista $L a$ Lecture littéraire (2014). Sin embargo, a pesar de la heterogeneidad que allí encontramos, podemos percibir dos rasgos comunes que lo atraviesan y que determinan el modo de pensar el texto en críticos franceses contemporáneos.

En primer lugar, la implicación del fantasma como suplemento de lo que en el sujeto falta, atentando contra la recreación de la propia identidad en el sentido hollandiano. En este sentido, podemos leer en el artículo de Serge Bédère: "lo que está en cuestión toca la relación de uno y otro respecto al fantasma [...], como punto que sostiene la estructura, que vuelve soportable por un efecto de juego de manos el desgarro interno de todo sujeto humano que se ve dividido por la operación del lenguaje y lo inaccesible del deseo" (2014: 102).

En segundo lugar, la escritura como consecuencia de esta falla, como expresión de la articulación entre la resonancia de inconsciente y la configuración fantasmática. Así, en el trabajo de Karl Canvat, encontramos la siguiente sentencia: "Es porque no se posee que el sujeto escribe" (2014: 77). Por su parte, y en el sentido en que la noción aglutina ciertos acuerdos, Nancy Murzilli señala que “aún si las acepciones de la noción de contra-texto son

intercambia el afecto y el significado, subordinando de hecho la sensación a la construcción de sentido" (2008: $161)$. 
divergentes, la mayoría parecer converger hacia la idea de que se trata de un texto verbalizado, estructurado y preferentemente escrito" (2014: 159). La escritura del contra-texto (que no remite necesariamente al comentario o al texto que el crítico elabora como respuesta, sino que supone la representación del texto que todo lector construye durante su lectura) es, por lo tanto, un proceso fallido de conocimiento del texto y de escritura de sí. En la medida en que implica una reacción (afectiva y simbólica) como efecto de la resonancia de los inconscientes, el contra-texto no es un puro efecto de lectura sino también un modelador: ni previo ni posterior, la temporalidad en la lectura se juega en una lógica de la duración y la retroacción. En este sentido, podemos decir que el contra-texto es así el texto desde donde se lee, el texto que se lee y el texto que se escribe como resultado de lo que se lee. $\mathrm{O}$ bien, el contra-texto está habitado por afectos y representaciones donde no todo puede ser elaborado simbólicamente, esto es, cuya publicación narra también el fracaso de la escritura.

El reconocimiento de esta condición epistemológica fundamenta, por lo tanto, un posicionamiento crítico que está en el centro de aquello que Marc Escola llama un cambio de paradigma en los estudios literarios franceses contemporáneos. Por un lado, se presenta el abandono de un objeto y la constitución de otro: el abandono del texto delimitado por un marco de referencia estable, que las teorías de la recepción -sobre todas aquellas vinculadas al psicoanálisis - vendrían a poner bajo sospecha, en su existencia ontológica, y en un acceso que se revela imposible, escapando a la posibilidad de una ciencia de lo general; la constitución del contra-texto como objeto, ciencia de lo particular que, fundamentada en una epistemología negativa -la de la inexistencia del texto más allá de su creación receptiva-, se desplaza de la hermenéutica a la poética y liga el acto de leer con el de escribir. Por otro lado, surge una crítica consecuente a esta reformulación del objeto, que asume distintos nombres y que en su vertiente psicoanalítica -que es la que hemos querido trazar sobre todo en este artículo- se ve particularmente representada por Pierre Bayard y su crítica intervencionista.

\section{La crítica intervencionista}

Haciéndose eco de la noción de contra-texto, Pierre Bayard entiende la lectura en términos de "intervención contra-transferencial" (2002: 164), dando un lugar fundamental al fantasma y subrayando como consecuencia una inestabilidad del objeto que la disciplina parece resistirse a admitir. En la veintena de ensayos que ha publicado desde principios de los '90, Bayard no ha dejado de insistir en el carácter móvil del texto, como podemos ver en su libro Le hors-sujet: "Movilidad que la teoría literaria tiende a descuidar desde que olvida que el texto no es el mismo para dos sujetos, ni para dos tiempos del mismo sujeto" (1996: 155). Bayard asume así una manera de entender el texto que se opone a su irreductibilidad material, de la misma manera que Mukarvosky veía la necesidad de separar el artefacto del objeto-estético. Pero a diferencia del teórico checo, elabora lo que llama una concepción re- 
lativista (cercana a la pragmática fisheana), en oposición a una concepción hermenéutica que estaría todavía centrada en la estabilización ejercida bien por el autor, bien por la estructura textual. Bayard se ve conducido así, en Enquête sur Hamlet (2002), a distinguir entre texto general (texto mítico inaccesible que cierta ingenuidad teórica asocia a su materialidad) y el texto particular (efecto del acontecimiento de la lectura):

Este cambio de perspectiva se liga con un descentramiento del texto hacia el lector, devenido, en detrimento del texto, la medida y la unidad. Es en el polo de la lectura, después y lejos de la escritura de la obra, que el texto se inventa, en un nacimiento singular que, abandonando la esperanza de reencontrar un día el paraíso perdido del texto general, se ofrece como un nuevo campo para la investigación crítica (2002: 48).

Si el texto singular configura un nuevo campo para la crítica, no puede devenir su objeto en tanto la contingencia atraviesa su estatuto ontológico e impide toda generalización. El objeto de estudio, por ello, parece establecerse no en el texto como producto singular, sino en las leyes de su elaboración, en otras palabras: en la lectura como experiencia cognoscitiva, como marco de referencia. Es la razón por la cual los elementos propios de una teoría del texto se abordan desde la perspectiva de una teoría de la lectura de corte psicoanalítico. Tal es el caso de las figuras retóricas - que Bayard estudia desde lo que llama, en Le paradoxe du menteur, la "retórica freudiana"-; tal es el caso, también, de las relaciones intertextuales que, cercanas a la noción de interlectura de Bellemin-Noë $1^{17}$, se entienden como una operación del lector antes que como una propiedad del texto, es decir, como una "intertextualidad subjetiva”: "[es necesario] desplazar la pregunta habitual de la intertextualidad (¿qué relación hay entre textos?) hacia otra diferente (¿qué relación se crea entre los textos?). [...] Lo que conduce a recordar que toda lectura implica un sujeto y que todo sujeto es ante todo un sujeto que asocia" (1996: 98-99).

Los límites de un texto, por lo tanto, se establecen a partir de una cartografía particular delineada cada vez por los recortes textuales que suscita la asociación del lector de acuerdo a particularísimos modos de ser de la intertextualidad. Así entendido, el pensamiento de Bayard parece recurrir a un pantextualismo en el que una consciencia lectoral asume la regulación interactiva de los textos, resignificando cada significante en los juegos sintagmáticos y paradigmáticos que asumen en el entramado de un con-texto también móvil.

Esta es el motivo por el cual Bayard elabora una serie de conceptos que procuran definir este contexto en términos de un pantextualismo que pivota entre la singularidad del sujeto y la comunidad que regula el relativismo. Por un lado, propone la noción de biblioteca colectiva como conjuntos de libros en los que reposa una cultura en un momento dado: "El

17 En Plaisirs de vampire (2001), Bellemin-Noël propone la noción de interlectura para referirse a los ecos de otros textos que un lector percibe en un texto a partir de sus lecturas personales. En este sentido, diferencia la "alusión", como referencia explícita establecida por el texto, de la evocación, donde "nada indica que el autor procedió deliberadamente en tal referencia ni que la mayoría de los lectores la identificará” (2001: 23). 
libro no cambia materialmente, pero, en tanto que elemento de la biblioteca colectiva, sufre modificaciones. [...] Prestar interés al contexto es recordar que un libro no está fijado de una vez por todas, sino que constituye un objeto móvil (2007: 158). La biblioteca colectiva subraya el carácter textual del contexto, pues la lectura de un libro no se restringe a los límites que una encuadernación le impone; antes bien, está determinada por un contexto formado por un conjunto de libros que definen una comunidad de lectura y que constituyen el verdadero estatuto del texto.

Así, el contexto mismo no puede ser establecido como un conjunto de elementos exhaustivamente determinados, porque su propia naturaleza textual imposibilita su clausura y delimitación, esto es, porque requiere una interpretación. Un libro es móvil porque la biblioteca colectiva desde el cual se lee es también móvil, en cuanto ella misma está compuesta de $\operatorname{libros}^{18}$.

Desde este punto de vista, al leer un texto se lee un conjunto de relaciones intertextuales que constituyen una situación de discurso y un marco de decisión que definen lo que podemos entender por contexto. Pero este último, en cuanto tiene una naturaleza textual, está sujeto a la interpretación y resulta, por lo tanto, tan inestable como el texto.

Ahora bien, el desbordamiento del texto, la dificultad de establecer sus límites, no se produce sólo por efecto de la biblioteca colectiva desde la cual se lee. Es necesario considerar también la inscripción del sujeto a partir de un intertexto privilegiado al que Bayard llama libro-interior, ligado estructuralmente al fantasma y entendido como un "conjunto de representaciones míticas, colectivas o individuales, que se interponen entre el lector y todo nuevo escrito" (2007: 81). Ampliamente inconsciente, el libro-interior funciona como un filtro que determina la lectura en la medida en que trabaja los textos en busca de su propia escritura que es, finalmente, imposible. No es casual que esta noción sea propuesta en el irónico ensayo de Bayard titulado Comment parler des livres que l'on n'a pas lus? (2007), porque lo que expresa la idea de la no-lectura es no sólo la imposibilidad de leer los textos con los que nos relacionamos, sino también la imposibilidad de leer el propio libro-interior como incesante proceso de escritura de lo que se resiste a la simbolización. En este sentido, el sujeto es entendido como una articulación intertextual entre el texto que lee, la biblioteca colectiva y personal en la que habitan los textos leídos y el libro-interior que busca escribirse cada vez.

Entramos aquí en el punto nodal de la concepción bayardiana del texto, puesto que la intertextualidad subjetiva supone no tanto el modo en que el lector instituye los límites del texto a partir de su relación con otros y a partir del significado que cada significante adquiere por las relaciones sintagmática que la asociación habilita, sino más bien porque existe una intertextualidad privilegiada, o bien un texto que regula las asociaciones intertextuales

18 Si bien, en Comment parler des livres que l'on n'a pas lus? (2007), Bayard emplea la noción de libro, es importante destacar que el autor insiste en la separación entre el soporte material y el texto: "Lo que evocamos al hablar de un libro designa un conjunto de límites inciertos, que es un universo de pensamiento tanto menos reductible a un soporte material cuanto cada lector participa en su constitución” (2015: 27). 
(incluido el autor como texto, incluido el contexto como marco de decisión de los sentidos del texto) y que remite a una concepción del lector en términos intertextuales, es decir, en términos de disposición a establecer una topología textual, una delimitación determinada en cada experiencia singular de lectura y cuyo resultado es el texto en tanto tal.

¿Qué es, entonces, un texto? Cercano a la pragmática de Stanley Fish -en un frase que incluso nos permite sospechar un guiño a Is There a Text in This Class?-, Bayard responde:

Un texto no es sólo un texto, que no es otra cosa que el motivo, el soporte o el pretexto. Es además todo el universo de palabras y de imágenes que la implicación de un sujeto constituye. El texto no existe antes de esta constitución que hace que dos textos de estudiantes sentados uno al lado del otro en la clase de literatura inglesa difieran entre sí tan sensiblemente como si un malentendido los hubiese hecho comprar obras diferentes (2002: 64-65).

El texto surge entonces como efecto de la implicación del sujeto, entendido como un marco de referencia que regula la intertextualidad entre el "pre-texto", la biblioteca colectiva y el libro-interior. Desde esta perspectiva, el contra-texto, como "intervención contra-transferencial", puede ser entendido como el intento fallido de escritura del libro-interior, un modo de ser de las relaciones intertextuales subjetivas que se configuran en el lector.

Tal posición ha permitido a Bayard fundamentar un tipo de crítica a la que llama intervencionista y cuya característica central radica en el pasaje a la escritura como operación de lectura, como una narración en segundo grado de la imposibilidad de lectura del texto y de lectura de sí -en términos de Paul de Man (1979)-: una alegoría de la lectura. Esto nos permite detectar dos tipos de crítica intervencionista.

La primera supone la intervención como reescritura del texto y se pone en escena en la trilogía del mejoramiento (Bayard, 2010a): Le hors-sujet (1996), Comment améliorer les œuvres ratées? (2000) y Et si les œuvres changeaient d'auteur? (2010b). El primero de estos ensayos se propone reducir la Recherche mediante la eliminación de sus digresiones. Pero la eliminación no es la operación intervencionista porque, en efecto, nunca logra identificarse con certeza una digresión. La intervención pasa por las técnicas de identificación de las digresiones: el desplazamiento, la supresión o el injerto. El segundo libro de la trilogía implica intervenciones de estilo, de tiempo, persona, así como la supresión de fragmentos o la inclusión de injertos, bajo el pretexto de mejorar obras de grandes escritores que Bayard considera malogradas - con el criterio de la posibilidad de inscribir o no el fantasma del lector en el texto-. El tercero, siguiendo un desafío borgeano, implica la operación de transformación del autor, reatribuyendo obras de un escritor a otro y operando así una transformación del texto. La crítica intervencionista ejecutada en esta trilogía trabaja a doble vínculo con la teoría y la literatura. Si supone ya ejercicios de reescritura, estos ejercicios significan, en bucle, un actuar teórico: si se pretende resumir la Recherche, la intervención mediante el desplazamiento, supresión o injerto de digresiones no significa tanto una rees- 
critura de la obra como la puesta en evidencia de la imposibilidad de establecer su centro y, con ello, el acceso al objeto textual.

Con lo que podemos llamar la trilogía de los universos posibles, Bayard radicaliza su apuesta y lleva a cabo una segunda forma de crítica intervencionista ligada a una escritura de sí. Un elemento central de esta escritura de sí se exhibe en los últimos ensayos publicados mediante la noción de personaje-delegado, a la que Bayard define en los siguientes términos: "personaje imaginario, enviado a una obra u otro período histórico diferente al nuestro, con el objetivo de vivir un experimento imaginario" (2015: 156). El experimento imaginario remite tanto a la posibilidad de recrear una escritura deseada como al modo de ponerse en el lugar de otro para imaginarse en diferentes situaciones y vehiculizar modos de ser.

Así, en Aurais-je sauvé Geneviève Dixmer? (2015), Bayard asume el rol de Maurice, protagonista de Le Chevalier de Maison-Rouge de A. Dumas (donde el dilema tiene que ver con salvar o no a una militante contrarrevolucionaria), con el fin de articular una fantasía (salvar a Geneviève Dixmer, siguiendo un anhelo de su lectura adolescente) y experimentar su propia subjetividad en situaciones que le resultan ajenas y por ello facilitadoras de subjetivación (¿sería capaz de salvar a Geneviève Dixmer?). El personaje-delegado es presentado explícitamente en este libro como herramienta de reescritura - de la novela de Dumas y del libro-interior- que es a la vez una respuesta figurada, en cuanto supone una desviación afectada por el uso de distintos dispositivos técnicos: los tropos (la elipsis, el resumen, la prolepsis, la analepsis), el injerto de citas y la alteración de la persona (que pasa del $i l$ al je), en un gesto ejemplar de reescritura del yo que busca, dice el autor, "la versión más cercana a aquella que imaginé en mis fantasías adolescentes, [intentando] producir la obra que siempre tuve ganas de leer" (Bayard, 2015: 36).

El objeto de la crítica deja por lo tanto de ser el texto, y la mirada se desplaza hacia el contra-texto como efecto de lectura. No es extraño, por ello, que el nuevo paradigma que, según Marc Escola, está emergiendo en los estudios literarios franceses suponga un desplazamiento hacia la retórica. En este sentido, la nueva crítica emergente se adapta muy bien al modo en que Harold Bloom la concebía en su Anatomía de la influencia: "La crítica literaria, tal como yo pretendo practicarla, es en primer lugar literaria, es decir, personal y apasionada. (...) cualquier distinción entre vida y literatura es engañosa" (2011: 18). 


\title{
6. A modo de conclusión: hacia un nuevo paradigma
}

\author{
Deseo una poética de la lectura deformante y desnaturali- \\ zante, que podría ayudarnos también a definir mejor qué es el \\ texto para la investigación literaria. Mi generación creció en \\ una especie de fetichismo del Texto, que en otros tiempos fue \\ un grito de guerra. Ha llegado el momento de elegir nuestro \\ propio camino. \\ (F. Schuerewegen)
}

Si Marc Escola tiene razón y se está operando una transformación paradigmática en los estudios literarios franceses, tal transformación se corresponde, nos parece, con un desplazamiento del objeto, fracturado y reconfigurado espacialmente tras el paso de las teorías de la recepción y de la deconstrucción.

Tal desplazamiento habría supuesto un abandono del texto como objeto y un pasaje a lo que querríamos llamar un hipercontratexto, es decir, una topología textual cuyas fronteras se establecen en cada acto de lectura por razones estructurales del texto (que afectan sus límites internos) y por motivos estructurales del sujeto de la lectura (que afectan los límites externos del texto).

En este artículo nos hemos detenido en estos últimos, indagando en teorías de la recepción que surgieron a partir de la década de los 60 -sobre todo en aquellas que, preocupadas por los procesos psicológicos que intervienen en la lectura, recurrieron al psicoanálisis-. Creemos que, en esta tradición, cuya manifestación conceptual es la noción de contra-texto, se asienta un nuevo modo de pensar la crítica literaria en los estudios literarios franceses contemporáneos.

El contra-texto parece emerger entonces como sustituto de un viejo objeto (el texto) que salva el hiato con una teoría nueva, según la expresión de Louis Hay citada en la introducción. Se trataría de un objeto nuevo cuyo trasfondo psicoanalítico procura una epistemología negativa (en el sentido en que subraya la imposibilidad cognoscitiva más allá de la producción escrita que surge como efecto). Así, lo cognoscible es el efecto de la lectura que en su movilidad constante resulta, sin embargo, incesantemente inaprensible. La epistemología se liga a una poética y la lectura a una escritura, además de que la crítica asume diversas formas en este nuevo paradigma, entre ellas la crítica intervencionista de Pierre Bayard.

Podría verse en Roland Barthes un punto de bisagra en esta dirección: en su abandono del estructuralismo hacia una crítica articulada a un decir literario -o bien, hacia una dificultad de ese decir, una puesta en escena de su imposibilidad- frente al texto como objeto, cuya última expresión es ese fantástico curso que supuso La préparation du roman. Observamos allí una concepción de la lectura como deseo de escritura, y de la escritura como verbo intransitivo: la crítica deja ser de escritura sobre algo, y se vuelve simple y llanamente escritura de algo. El proyecto de Barthes remite a un "Querer-escribir" cuyo efecto no parece lejano 
a lo que entendemos como contra-texto, en cuanto aparecen aquí, junto al deseo de escritura ligado a la lectura, otros tres elementos que definen esta noción tal como la hemos trabajado en este artículo.

En primer lugar, encontramos el componente fantasmático: "querer-escribir tiene siempre un objeto fantasmático. En consecuencia, habría fantasmas de escritura; y hay que tomar estar expresión en su fuerza deseante, es decir, comprender el fantasma del querer escribir algo del mismo modo que los fantasmas sexuales" (Barthes, 2015: 32).

En segundo lugar, aparece la imposibilidad ligada a su escritura, que Barthes reconoce en la medida en que advierte que su curso podría haberse llamado, también, la novela imposible, como un espectro que se resiste a su escritura.

Finalmente, la necesidad de un retorno a la enseñanza retórica que, abandonada hacia el siglo XIX, desplazó el arte de la escritura por el de la lectura. Retorno ligado a la técnica (téchne), pero también a la pasión (pathos): “Amar un texto es más o menos desear hacerlo, desear rehacerlo. Yo diría que del placer de lo producido se infiere un deseo de producción" (Barthes, 2015: 77).

El contra-texto es el efecto fallido - por cuanto escritura de una novela imposible, en incesante preparación- de ese "querer-escribir". Es un aspecto psicoanalítico de este nuevo objeto que una trasformación paradigmática parece hacer emerger y cuyo otro componente, ligado a las fracturas internas y el universo de sus posibles (formalizado en la teoría de los textos posibles de Escola o el método postextual de Franc Schuerewegen), deberá ser complementado en otra investigación. Mientras tanto, el aspecto psicoanalítico de este nuevo objeto nos permite vislumbrar ya cierto aire de cambio en los modos de pensar la crítica, al menos en el caso francés. Ha llegado el momento, como dice Schuerewegen (2015), de abandonar el fetichismo del Texto y hacer el propio camino.

\section{Referencias bibliográficas}

Barthes, Roland. 2002. "De l'œuvre au texte” in Euvres Complètes, Tomo III. Paris, Seuil.

BARThes, Roland. 2015. La préparation du roman. Paris, Seuil.

Bayard, Pierre. 1993. Le paradoxe du menteur. Sur Laclos. Paris, Minuit.

Bayard, Pierre. 1996. Le hors-sujet. Proust et la digression. Paris, Minuit.

BAYARD, Pierre. 2000. Comment améliorer les æuvres ratées? Paris, Minuit.

Bayard, Pierre. 2002. Enquête sur Hamlet. Le dialogue de sourds. Paris, Minuit.

BAYARD, Pierre. 2007. Comment parler des livres que l'on n'a pas lus? Paris, Minuit.

BAYARD, Pierre. 2010a. Et si les auvres changeaient d'auteur? Paris, Minuit. 
BAYARD, Pierre. 2010b. "Comment j'ai fait régresser la critique" in Zimmerman, Laurent (éd.). Pour une critique décalée. Nantes, Cécile Defaut, 19-37.

Bayard, Pierre. 2015. Aurais-je sauvé Geneviève Dixmer? Paris, Minuit.

BÉDÈRE, Serge. 2014. "Le contre-texte, ou du face à face silencieux entre la subjectivité du lecteur et celle de l'auteur" in La Lecture littéraire, $\mathrm{n}^{\circ}$ 12, 93-104.

Bellemin-NoËL, Jean. 1977. Vers l'inconscient du texte. Paris, PUF.

Bellemin-NoËL, Jean. 2001. Plaisirs du vampire. Paris, PUF.

Bloom, Harold. 2011. Anatomía de la influencia. Buenos Aires, Taurus.

BRUNER, Jerome. 2012. Realidad mental y mundos posibles. Buenos Aires, Gedisa.

Canvat, Karl. 2014. "L'Autre scène du texte ; contre-texte et in-dicible" in La Lecture littéraire, $\mathrm{n}^{\circ} 12,71-92$.

Charles, Michel. 1995. Introduction à l'étude des textes. Paris, Seuils.

Clancier, Anne. 1977. “Qu'est-ce qui fait courir Boris Vian ?” in Arnaud, Noël \& Henri Baudin (éds.). Boris Vian, Colloque de-Cerisy-La-Salle. Paris, UGE, 49-86.

Clancier, Anne. 2014. "Questions à Anne Clancier sur le contre-texte" in La Lecture littéraire, $\mathrm{n}^{\circ} 12,11-14$.

Compagnon, Antoine. 1998. Le démon de la théorie. Paris, Seuil.

Couturier, Maurice. 1995. La figure de l'auteur. Paris, Seuil.

De Man, Paul. 1979. Allegories of Reading. Minneapolis, University of Minnesota Press.

DerridA, Jacques. 1971. De la gramatología. Buenos Aires, Siglo XXI.

Derrida, Jacques. 1979. "Living On” in Bloom, Harold (ed.). Deconstruction and Criticism.

London, Routledge \& Keagan Paul Ltd.

Derrida, Jacques. 2010. La vérité en peinture. Paris, Flammarion.

EAgleton, Terry. 2002. Una introducción a la teoría literaria. México, FCE.

Escola, Marc. 2011. "Petites querelles du Grand Siècle" in Les Facultés de juger, n 64, $37-46$.

Fish, Stanley. 1980. Is There a Text in This Class? Massachusetts, Harvard University Press.

FISH, Stanley. 1982. "With the Compliments of the Author: Reflections on Austin and Derrida" in Critical Inquiry, vol. 8, no 4, 693-721.

Freund, Elisabeth. 1987. The Return of the Reader. London, Methuen.

Garayalde, Nicolás. 2018a. "La lectura del tiempo en la obra de Pierre Bayard" in Çedille, revista de estudios franceses, $\mathrm{n}^{\circ} 14,221-243$. 
GARAYAlde, Nicolás. 2018b. "La resurrección del autor en la crítica francesa actual (20082011). El caso de la crítica de reatribución de Pierre Bayard" in Co-herencia, vol. 15, $\mathrm{n}^{\circ} 29$, 251-281.

Garayalde, Nicolás. 2019. "Una poética de la delectura" in Álabe, no 20, 1-22.

Glaudes, Pierre. 1990. Contre-textes. Essais de psychanalyse littéraire. Toulouse, Ombre.

Glaudes, Pierre. 1993. "Le contre-texte" in Littérature, nº 90, 88-101.

HaY, Louis. 1985. "Le texte n'existe pas” in Poétique, nº 62, 147-158.

Holland, Norman. 1975. 5 Readers Reading. New Haven and London, Yale University Press.

Holland, Norman. 1992. The Critical I. New York, Columbia University Press.

Holland, Norman. 2008. Literatura, lectura y neuropsicoanálisis. Córdoba, Alción.

IsER, Wolfgang. 1987. El acto de leer. Teoría del efecto estético. Madrid, Taurus.

ISER, Wolfgang. 1989. "La estructura apelativa de los textos" in Warning, Rainer (comp.). Estética de la recepción. Visor, Madrid, 133-148.

IsER, Wolfgang, Norman Holland \& Wayne Bоотн. 1980. "Interview: Wolfgang Iser" in Diacritics, vol. $10, \mathrm{n}^{\circ} 2,57-74$.

JAUSS, Hans-Robert. 1987. "El lector como instancia de una nueva historia de la literatura" in Mayoral, José Antonio (comp.). Estética de la recepción. Madrid, Arco, 59-85.

Lanson, Gustave. 1966. Histoire de la littérature française. Paris, Hachette.

Littau, Karin. 2008. Teorías de la lectura. Buenos Aires, Manantial.

MaCÉ, Mariel. 2004. "Description et interprétation: l'objet de la poétique" in ATH. Paris, Fabula: <https://www.fabula.org/ressources-atelier.php $>[12 / 09 / 2019]$.

Miller, Jacques-Alain. 2010. Extimidad. Paidós, Buenos Aires.

Miller, Joseph Hillis. 2005. "Line" in Wolfreys, Julian (comp.). The J. Hillis Miller Reader. California, Standford University Press, 235-250.

Monlau, Pedro Felipe. 1856. Diccionario etiomológico de la lengua castellana. Rivadeneyra, Madrid.

Mukarovsky, Jan. 2000. "El arte como hecho sígnico” in Signo, función y valor. Bogotá, Plaza y Janés Editores.

Mukarovsky, Jan. 2011. Función, norma y valor estéticos como hechos sociales. Buenos Aires, El cuenco de plata.

Murzilli, Nancy. 2014. "L'invitation au contre-texte dans l'écriture contemporaine" in $L a$ Lecture littéraire, $\mathrm{n}^{\mathrm{o}}$ 12, 159-174. 
PicARD, Michel. 1986. La lecture comme jeu. Paris, Minuit.

PiCARD, Michel. 1989. Lire le temps. Paris, Minuit.

Rabinowitz, Peter. 2010. “Otras teorías orientadas al lector” in Selden, Raman (ed.). Historia de la crítica literaria del siglo XX. Madrid, AKAL.

Robin, Régine. 1989. "Extension et incertitude de la notion de littérature" in Angenot, Marc (éd.). Théorie littéraire. PUF, Paris, 45-49.

Schuerewegen, Franc. 2012. Introduction à la méthode postextuelle. Paris, Garnier.

Schuerewegen, Franc. 2015 “Texte” in Bouju, Emmanuel (éd.). Fragments d'un discours théorique. Paris, Cécile Defaut, 351-369.

Shklovski, Viktor. 2008. "El arte como artificio" in Todorov, Tzvetan (comp.). Teoría de la literatura de los formalistas rusos. Buenos Aires, Siglo XXI, 77-98.

Tinianov, Juri. 2008. "Sobre la evolución literaria" in Todorov, Tzvetan (comp.). Teoría de la literatura de los formalistas rusos. Buenos Aires, Siglo XXI, 123-139.

Tortosa, Francisco y Cristina Civera. 2006. Historia de la psicología. Madrid, McGraw Hill.

Wimsatt, William K. \& Monroe C. Beardsley. 1949. "The Affective Fallacy" in The Sewane Review, vol. 57, $\mathrm{n}^{\circ} 1,31-55$. 
